\title{
Effect of circuit training on selected health-related physical fitness components: the case of sport science students
}

\author{
Dessalegn Wase Mola® , Getachew Tesema Bayeta®
}

Department of Sport Science, College of Natural and Computational Sciences, Ambo University, Ethiopia.

\begin{abstract}
The purpose of this study was to evaluate the effects of circuit training on selected healthrelated physical fitness of $2^{\text {nd }}$-year sport science students at Ambo University, Ethiopia. The quasiexperimental research design was used in this study. For this study, all 39 students were considered as a sample with 22 males and 17 females by using the stratification sampling technique. Among 39 students, 19 of them were experimental groups $(E G, n=19)$ while the other 20 were considered as the control group ( $C G, n=20$ ) using a simple random sampling technique. The age of subjects was ranged from 19-22. The EG of the study received a supervised training program for 12 weeks and 3 days per week for $60-65$ minutes per session and CG did not receive the additional training which was designed for this study. The variables selected for this study were: Muscular endurance, muscular strength, and flexibility with their tests of push-up, wall squat and sit and reach test. Tests were taken two times at pre-test and posttraining. In this study, exercise was done with orientations, instructions, and supervision by the researcher and assistants. Data were analyzed by paired sample t-test and independent sample t-test. After the 12-week training program, the muscular endurance, muscular strength, and flexibility of the students are increased significantly in the experimental group $(\mathrm{p}<.05)$. The respective values did not change in the control group $(p>.05)$. The results showed that the circuit training program was effective to increase and maintain muscular strength, muscular endurance, and flexibility of the students. The present study indicated that 12 -weeks of well-designed physical fitness training enhanced the performance of sport science students at Ambo
\end{abstract}

University. Therefore, scientific-based training should be incorporated into the sports science curriculum training program to maximize the ability of the athletes.

Keywords. Flexibility, health-related physical fitness, muscular endurance, muscular strength.

\section{Introduction}

Circuit training is a form of conditioning combining resistance training and highintensity aerobics. It is designed to be easy to follow and target strength building as well as muscular endurance. An exercise "circuit" is one completion of all prescribed exercises in the program (Abdullah \& Omar, 2002). Circuit training is a significant way to improve mobility, strength, and stamina. The circuit training comprises of 6 to 10 strength exercises that are completed one exercise after another. Each exercise is performed for a specified number of repetitions or for a set time before moving on to the next exercise. The exercises within each circuit are separated by a short rest period, and each circuit is separated by a longer rest period. The total number of circuits performed during a training session may vary from two to six depending on your training level (beginner, intermediate, or advanced), your period of training (preparation or competition), and your training objective (Ortega et al., 2008; Alcaraz et al., 2008). 
The main problem related to physical fitness is its expected decrease after a period of detraining. Several authors confirm that after 8 to 12 weeks of detraining children lose a significant part of the physical fitness gains obtained. A possible solution for this problem could be the periodical introduction of short maintenance programs throughout the academic course. During these intervals, physical education teachers will be able to develop other curricular contents and at the same time, they could be improving the previous physical fitness gains (Ingle et al., 2006; Markovic, 2007; de Villarreal et al., 2009).

Educational areas are mainly attempting to increase the pupils' health level by using measures such as the improvement of their physical fitness through physical activities. It has been concluded that health promotion policies and physical activity programs should be designed to improve physical fitness (Ortega et al., 2008). The circuit training effectively reduces the time devoted to training while allowing an adequate training volume to be achieved moreover; it permits a greater motor engagement time. This methodology has multilevel effects on fitness, especially in beginners.

The effect of selected circuit training on muscular strength, flexibility, and muscular endurance is highly important. Many studies analyzed about Effects of the circuit training program. But there were no enough researches that studied the effects of selected circuit exercises in improving muscular strength, muscular endurance, and flexibility at the university level of students and here in our country.

Mayorga-Vega et al. (2013) conducted a study on the effects of a circuit training program on muscular and cardiovascular endurance. The purpose of this study is only to evaluate the effects of a circuit training program along with a maintenance program on muscular and cardiovascular endurance in children in a physical education setting. This study was not examined by muscular strength and flexibility.

Another study was done by Sonchan et al. (2017) on the effects of a circuit training program for muscle strength, agility, anaerobic performance, and cardiovascular endurance but, this study does not examine muscular Endurance and flexibility. The study aimed to examine the effects of a circuit training program on muscle strength, agility, anaerobic performance, and cardiovascular endurance.

The above two research works are not examining the effect of selected circuit training on a combination of muscular strength, flexibility, and muscular endurance. And it is not well-known that selected circuit training exercise is better in bringing improvements in physical fitness components. So this research was conducted to fill this gap. The general objective of this study was to evaluate the effect of circuit training on selected health-related physical fitness of $2^{\text {nd }}$-year sport science students in Ambo University, Ethiopia.

Therefore, the current study tried to examine the presence of a statistically significant difference between the experimental and control groups regard to muscular endurance training, muscular strength, flexibility training. To be effective and productive practice, sport science students are needed to be fit and good performers physically and mentally. If that so, circuit training exercise will be a means, and good intervention to improve physical fitness qualities of muscular strength, flexibility, and muscular endurance is highly important. So this study helped us to identify whether selected circuit training on the improvement of aerobic fitness, muscular strength, flexibility, muscular endurance, and body composition or not. It is an interesting topic for physical exercise scientists, physical education teachers, coaches, athletes, exercise physiologists, and other specialists in sports and exercise science. This study was expected to lay down the basis for future investigation in this area. 


\section{Methods}

\section{Study Design}

This study was a quasi-experimental research design for 12 weeks to implement scientificbased training and to see the effect of circuit training on selected health-related physical fitness of $2^{\text {nd }}$-year sport science students in Ambo University, Ethiopia. For this study, all 39 students were considered as a sample with 22 males and 17 females by using the stratification sampling technique. Among 39 students, 19 of them were experimental groups (EG, $n=19$ ) while the other 20 were considered as the control group (CG, $\mathrm{n}=20$ ) using a simple random sampling technique (Kothari, 2004). The age of the subject was ranged from 19-22. Subjects who fulfilled the health history and physical readiness questionnaire requirements were selected and participated in this study. Individuals who are free from acute or chronic disease and not having current physical and mental injury were included whereas the subjects contrary to the above criteria were excluded from the study. Since the study was intended to include volunteer participants and the ethical committee also understands as it has no problem with them, they decided to give the clearance verbally. The study was dealt with the ethical issues related to the investigation. The participation of subjects in this study is purely a voluntary activity and their right not to participate and can resign at any time was respected. Finally, the ethical consideration is certified with a strong agreement between the researcher and the athletes. The protocol was approved by the written consent form which was given and informed the concerned bodies. The training program was given to the experimental group for 12 weeks and 3 day pear weeks (Tuesday, Thursday, and Friday) 60-65 minutes per session. The Control group did not perform the additional training designed for this study. Tests were taken two times at pre-test and post-training. According to Markovic (2007) and de Villarreal et al.
(2009), 8 to 12 weeks of the training program is essential to maximize individuals' abilities.

\section{Methods and Procedures of Data Collection}

Quantitative data was collected from the variables. The variables for this study were Flexibility, Muscular Strength, and Muscular endurance. Primary data was gathered from the subjects by standard physical fitness tests. The tests were given at the beginning of the training and the end of 12 weeks. The data was recorded by the three data recorders who have been trained and oriented with how to collect data of pre-test and post-test (Reily \& Brooks, 1982). The Dependent variables of this study are muscular strength, muscular endurance, and flexibility.

Sit and reach flexibility test: A subject performs a short warm-up before performing a fitness testing. This test measures the flexibility of the lower back and hamstring muscles (Ashok, 2008). The equipment required was a special testing box and a ruler. The procedure of this test involves sitting on the floor with legs stretched out straight ahead. After some practice reaches, the subject reaches out and holds that position for one-two seconds while the distance is recorded. Three trials were given to the subject and the highest scores were recorded.

Push-up test for upper body endurance: A subject performs a short warm-up before performing a fitness testing. Push-ups measure the muscular endurance of the upper body muscles to include the shoulders, chest, and back of the upper arms. This fitness area is related to the use of force involving pushing motion. Standard push-ups are continued until failure (e.g. inability to continue due to muscle fatigue). Recruits assume a push-up position with feet together or up to twelve inches apart. Hands were placed approximately shoulderwidth apart with fingers facing forward. A partner recruit will in a position to extend a fist on the floor directly underneath the testing recruit's sternum. A proper push-up is when 
the testing recruit lowers the body and touches the fist with the sternum then returns up to the starting position with the elbows in a soft lock. Proper form is closely monitored. Three trials were given to the subject and the highest is a record (Armstrong, 2009).

Wall squat test for muscular strength: A subject performs a short warm-up before performing a fitness testing. This test was used to test the quadriceps strength. To undertake this test the researcher requires a warm dry location-gym, smooth wall, stopwatch assistant. The Wall Squat test was conducted as follows, the subject was Stand comfortable on both feet with your back against a smooth wall slide your back down the wall, there is to be a $90^{\circ}$ angle at the hip and knee, when the subjects are ready Lift one foot $5 \mathrm{~cm}$ off the ground the assistant starts the stopwatch Balance for as long as possible. The watch is stopped when they put their foot back on the ground; the researcher takes a test and then repeats the test with the other leg. The best time result was recorded as a score in the second (Armstrong, 2009).

\section{The Circuit Training Protocol}

The training program was given to the subjects for 12 weeks three times a week (Tuesday, Thursday, and Friday). The session has begun with an 8-10 minute general and specific warming-up period, followed by the main workout for 60-65 minutes of low to moderate intensity selected Exercise; then the session lasts up with 6-8 minutes cooling down activities. For the six weeks and then, the selected Circuit training exercises increased to high-intensity exercises slowly for the last six weeks. According to (Marković et al., 2007; de Villarreal et al., 2009), 8 to 12 weeks of a training program is essential to maximize individuals' abilities. The training program was scheduled for the participants and the exercise training was given by the researcher and his assistants. The Muscular Strength training, Muscular Endurance, and Flexibility training program will be progressed gradually from lower intensity drills to more advanced exercises particularly in an individual with less strength training experience. Low-intensity training exercise can be performed with an HRmax of $40 \%-60 \%$ consisting of running on the spot, push-up, side straddle hop, sit up, bend and reach, wide push-up, bicycle, knee bender, twisting sit up, swimmer, bench steps, split squats, military press, bench press, abdominal curls, rope jumping (done slowly). The moderate-intensity training exercises program consists of about $60 \%-70 \%$ HRmax. It includes the following exercises; split squat jumps, trunk jumps, lateral box push-offs, bounding with the rings, box drills with rings, lateral hurdle jumps, However, high-intensity training exercise workout may consist of about 70\%-85\% HRmax, and high-intensity training exercise includes zigzag hops, single-leg trunk jump, single-leg lateral hops and depth jumps. Progressive overload principles were incorporated into the program by increasing the number of sets of each exercise. The subjects were instructed to perform all jumps at maximal effort, maximal height or amplitude, and minimal ground contact time (Grosset et al., 2008).

\section{Statistical Analysis}

The collected data were analyzed using descriptive statistics and inferential statistics. Descriptive statistics involves; mean, standard deviation, frequency distribution, and graphics into meaningful ideas using SPSS Version 20 software to the selected physical fitness observed in the participants. Inferential statistics includes paired $t$-test was used to observe within-group difference from pre-test to post-test result for both experimental and control group. To justify the normality of the data under consideration, we also checked the normality through the histogram and Shapiro Wilk test so that the data is normal. The results of the study were analyzed by an independent samples t-test to compare the selected physical fitness variables between the control group and 
the experimental group. The level of significance was 0.05 .

\section{Results}

Table 1 shows the variables measured in the EG and CG in the pre-test and post-test. Significant increases in EG were found in Pushup and wall squat and $S \&$ RT after the 12-week circuit training program $(\mathrm{p}<.05)$. On the other hand, there was no significant difference between pre-and post-test in CG $(\mathrm{p}<.05)$. These results indicate that the circuit training increased the health-related physical fitness variables namely muscular endurance, muscular strength, and flexibility when compared with the control group.

Table 2 presents comparisons of push-up, wall squats, and S \& RT between EG and CG before and after the circuit training. The comparisons between groups applied for the pre-test revealed that there was no difference between variables $(p>.05)$. In the post-test, push-up, wall squats, and $S \& \mathrm{RT}$ were higher in EG than CG $(\mathrm{p}<.05)$.

\section{Discussion}

The major focus of this study was to implement scientific-based training and to see the selected type of exercise circuit training on selected health-related physical fitness of $2^{\text {nd }}$ year sport science students in Ambo University, Ethiopia. In this discussion section, the main findings of this study were that integrating muscular strength, muscular endurance, and flexibility training exercise with the regular training program of sport science students for 12 weeks brings significant improvement in their related physical fitness and physiological variables. Similarly, the results of the study were consistent with (Markovic, 2007; de Villarreal et al., 2009).

\begin{tabular}{|c|c|c|c|c|c|c|}
\hline Variables & Groups & Pre-test & Post-test & MD & $\mathrm{t}$ & $p$ \\
\hline \multirow[t]{2}{*}{ Push-Up (In number) } & EG & $18.0 \pm 3.90$ & $26.56 \pm 2.58$ & 8.53 & 9.123 & $.000^{*}$ \\
\hline & CG & $17.33 \pm 3.73$ & $17.20 \pm 4.27$ & -.133 & -.286 & .779 \\
\hline \multirow[t]{2}{*}{ Wall Squat (Sec) } & EG & $40.13 \pm 12.17$ & $73.33 \pm 9.33$ & 33.20 & 15.858 & $.000^{*}$ \\
\hline & CG & $40.66 \pm 8.86$ & $40.80 \pm 10.05$ & .133 & .112 & .912 \\
\hline \multirow[t]{2}{*}{ Sit and reach test $(\mathrm{cm})$} & EG & $9.60 \pm 6.53$ & $17.40 \pm 5.26$ & 7.80 & 13.472 & $.000^{*}$ \\
\hline & CG & $8.46 \pm 5.08$ & $9.13 \pm 4.01$ & .666 & 1.214 & .245 \\
\hline
\end{tabular}

\section{Table 2}

Comparisons of measured variables between EG and CG in both pre-test and post-test.

\begin{tabular}{|c|c|c|c|c|c|c|c|c|c|c|}
\hline \multirow{3}{*}{ Variables } & \multicolumn{5}{|c|}{ Pre-Test } & \multicolumn{5}{|c|}{ Post-test } \\
\hline & \multirow{2}{*}{$\mathrm{t}$} & \multirow{2}{*}{$p$} & \multirow{2}{*}{ MD } & \multicolumn{2}{|c|}{$95 \% \mathrm{Cl}$} & \multirow{2}{*}{$\mathrm{t}$} & \multirow{2}{*}{$p$} & \multirow{2}{*}{$\mathrm{MD}$} & \multicolumn{2}{|c|}{$95 \% \mathrm{Cl}$} \\
\hline & & & & Lower & Upper & & & & Lower & Upper \\
\hline Push-up & -.478 & .696 & -.66 & -3.52 & 2.19 & 7.22 & $.000 *$ & 9.33 & -11.97 & -6.68 \\
\hline Wall squat & .137 & .219 & .533 & -7.43 & 8.49 & 9.18 & $.000 *$ & 32.53 & -39.79 & -25.27 \\
\hline S\&RT & -.600 & .718 & -1.13 & -5.00 & 2.73 & 4.17 & $.000 *$ & 8.26 & -12.32 & -4.21 \\
\hline
\end{tabular}


The summary results of the study indicated that the training has a statistically significant change in the muscular strength of the subject. The finding of this study is supported by Mane \& Yadav (2011). Besides, the independent $t$-test supported that there was a statistically significant improvement in the comparison of experimental groups and control groups under the post-test than the corresponding pre-test.

The results indicated that experimental groups had statistically significant effects on increasing Muscular endurance; this is since the p-value is less than the level of significance. This study is consistent with the study by Shaikh \& Mallick (2012). The results of the independent $\mathrm{t}$-test indicated that there were statistically significant changes at the post-test than the corresponding pre-test in comparing the experimental and control groups. Thus, the results obtained in this study were consistent with the study by (Mayorga-Vega et al., 2013).

Considering the outcome of the Flexibility test of the experimental group, it was obvious that the Flexibility of the experimental group was significantly raised in the post-test. Thus since the $p$-value of this variable which is 0.00 is less than the level of significance, the 12 weeks of physical fitness training had a significant effect on increasing the flexibility of sports science the results were consistent with Baltaci et al. (2003).

Besides, the independent t-test presented under table 3 also supported that there was a statistically significant improvement in the comparison of experimental groups and control groups under post-test than the corresponding pre-test. Thus, the results obtained in this study were consistent with the study by (Baltaci et al., 2003).

Barbosa et al. (2002) conducted a study on the effects of resistance training on the sit-andreach test in elderly women. The training program resulted in a significant increase in the flexibility of elderly women. No significant differences were found in the control group. Likewise, this result was consistent with our research study that there was an improvement in the experimental group of those who took 12 weeks of intervention with the sit and reach test of flexibility.

\section{Conclusions}

Within the limitations of the present study, it was concluded that the health-related physical fitness treatment of Experimental groups had shown significant improvement in the studied health-related physical fitness variables namely muscular strength, muscular endurance, flexibility when compared with the control group as well as the baseline information after they underwent 12-weeks of Ambo university $2^{\text {nd }}$-year sport science students practicing. Selected circuit training exercises can improve the health-related physical fitness variables of sport science students and reduce the chances of sports-specific injury.

Generally, the present study indicated that 12-weeks of well-designed circuit training physical fitness training enhanced the performance of the trainer. Therefore, in addition to the usual training program, additional training like scientific-based training should be incorporated in the class scheduled training program to maximize the ability of the student.

\section{Acknowledgments}

The researchers wish to acknowledge the Department of Sport Science, College of Natural and Computational Sciences, and Ambo University for the support and approval to carry out the study. We also appreciate the enthusiasm and co-operation of the participants.

\section{Conflict of Interest}

The authors declared no potential conflicts of interest concerning the study.

\section{References}

Abdullah, N., \& Omar F. (2002). Sport Psych. Kuala Lumpur: Utusan Publication. 
Alcaraz, P.E., Sánchez-Lorente, J., \& Blazevich, A.J. (2008). Physical performance and cardiovascular responses to an acute bout of heavy resistance circuit training versus traditional strength training. J Strength Cond Res, 22(3), 667-671.

Armstrong, M.E.G. (2009). Youth fitness testing in South Africa primary school children: national normative data, fitness and effects of socioeconomic status. Doctoral thesis, Department of Human Biology, University of Cape Town, South Africa.

Ashok, C. (2008). Test your physical fitness. India: Gyan Publishing House.

Baltaci, G., Un, N., Tunay, V., Besler, A., \& Gerçeker, S. (2003). Comparison of three different sit and reach tests for measurement of hamstring flexibility in female university students. $\mathrm{Br} \mathrm{J}$ Sports Med, 37(1), 59-61.

Barbosa, A. R., SantarÉm, J. M., Jacob Filho, W., \& Marucci, M. D. F. N. (2002). Effects of resistance training on the sit-and-reach test in elderly women. J Strength Cond Res, 16(1), 14-18.

de Villarreal, E.S., Kellis, E., Kraemer, W.J., \& Izquierdo, M. (2009). Determining variables of plyometric training for improving vertical jump height performance: a meta-analysis. J Strength Cond Res, 23(2), 495-506.

Grosset, J.F., Piscione, J., Lambertz, D., \& Pérot, C. (2009). Paired changes in electromechanical delay and musculo-tendinous stiffness after endurance or plyometric training. Eur J Appl Physiol, 105(1), 131-139.

Ingle, L., Sleap, M., \& Tolfrey, K. (2006). The effect of a complex training and detraining programme on selected strength and power variables in early pubertal boys. J Sports Sci, 24(9), 987-997.
Kothari, C.R. (2004). Research methodology: methods and techniques. New Delhi: New Age International Ltd.

Mane, M.M., \& Yadav, S.K. (2011). The effects of circuit training for the development of vertical jumping ability, endurance, agility and skill ability in football players' boys aged 10 to 12 years. Variorum, Multi-Disciplinary e-Research Journal, 1(4), 1-8.

Markovic, G. (2007). Does plyometric training improve vertical jump height? a meta-analytical review. Br J Sports Med, 41(6), 349-355.

Mayorga-Vega, D., Viciana, J., \& Cocca, A. (2013). Effects of a circuit training program on muscular and cardiovascular endurance and their maintenance in schoolchildren. J Hum Kinet, 37, 153-160.

Ortega, F.B., Ruiz, J.R., Castillo, M.J., \& Sjöström, M. (2008). Physical fitness in childhood and adolescence: a powerful marker of health. Int $J$ Obes, 32, 1-11.

Reily, T., \& Brooks, G. (1982). Investigations of circadian rhythms in metabolic response to Exercise. Ergonomics, (25), 1098-1197.

Shaikh, A., \& Mallick, N.I. (2012). Effects of plymetrics training and weight training on selected motor ability components among university male students. International Journal of Advancements in Research and Technology, 1(6): 1-9.

Sonchan, W., Moungmee, P., \& Sootmongkol, A. (2017). The effects of a circuit training program on muscle strength, agility, anaerobic performance and cardiovascular endurance. World Academy of Science, Engineering and Technology, International Journal of Sport and Health Sciences, 11(4), 176-179. 